\title{
Promoting extended student talk in an EFL classroom
}

\author{
Fatma Gümüşok a * (D), Gözde Balıkçı b† \\ a Department of Foreign Language Education, Middle East Technical University, Ankara 06800, Turkey \\ ${ }^{b}$ Department of Foreign Language Education, Kahramanmaraş Sütçü İmam University, Kahramanmaraş 46050, \\ Turkey
}

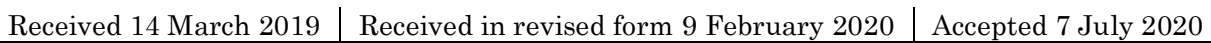

\begin{abstract}
APA Citation:
Gümüşok, F. \& Balıkçı, G. (2020). Promoting extended student talk in an EFL classroom. Eurasian Journal of Applied Linguistics, 6(2), 205-228.
\end{abstract}

Doi: $10.32601 /$ ejal.775799

\begin{abstract}
This study aims to analyze the way one EFL teacher maintains and promotes extended student talk in an EFL Listening and Speaking Course at tertiary level via conversation analytic perspective. Promoting extended student turns is one of the main goals of meaning and fluency contexts in language classroom discourse (Seedhouse, 2004), thus, it is of quite importance to study extended student talk in a microanalytic and detailed way. The data were collected from an EFL class at a private university in Turkey. Listening and Speaking course was audio-recorded for nine classroom hours over five weeks. The data were transcribed using Jefferson transcription system (Jefferson, 2004). The study revealed that the participants systematically follow an organized sequential path leading to extended learner turns. The sequential unfolding of eliciting extended student talk involves alternative questions as a sequence opener and elaboration questions as follow-ups. When students initiate word search sequence, the teacher addresses students' emergent word searches and withholds evaluation turn via minimal response tokens. In addition, on-the-spot decision making such as providing planning time stimulates extended learner talk in subsequent turns. The findings offer some suggestions for the practitioners who would like to promote extended student talk and facilitate learning opportunities in their language classes and contribute to the EFL classroom interaction research.
\end{abstract}

(C) 2020 EJAL \& the Authors. Published by Eurasian Journal of Applied Linguistics (EJAL). This is an open-access article distributed under the terms and conditions of the Creative Commons Attribution license (CC BY-NC-ND) (http://creativecommons.org/licenses/by-nc-nd/4.0/).

Keywords: classroom research; EFL classroom; extended student talk; conversation analysis; teacher questions

\section{Introduction}

Classroom research, which investigates what is actually happening in a classroom, originates from the field of teacher education. Teacher trainers' concern for providing feedback to prospective teachers about their classroom performance is the source of classroom research. In the light of teacher training as a parent discipline for

\footnotetext{
* Corresponding author. Tel.: +0-312-210-6498

E-mail address: fatmagumusok@gmail.com

† gozdebalikci2@gmail.com

http://dx.doi.org/10.32601/ejal.775799
} 
classroom research, early studies, firstly having adopted a prescriptive approach to teacher behavior, dealt with describing teacher performance by means of certain observation tools like FIAC, FLint, FOCUS, etc. (Allwright \& Bailey, 1991). Teacher educators' efforts to come up with an answer for what constitutes effective teaching became so alluring and intense that classroom research comes to the foreground with its own boundaries as a research area to be developed.

Chaudron (1988) suggests that as an enlarging field of research, classroom research deals with four major issues regarding the effectiveness of classroom instruction: 1) learning from instruction, 2) teacher talk, 3) learner behaviour, and 4) interaction in the classroom. Among these issues, teacher talk has always drawn researchers' attention who adopt different conceptual and methodological approaches to analyzing classroom discourse (Sert, 2013; Walsh, 2002; Waring, 2009). Since language classes are unique in terms of the status of language which is both the content of instruction and the medium of instruction (Allwright \& Bailey, 1991; Cook, 2013; Seedhouse, 2004), teacher talk both functions as input to language learners and the vehicle to orchestrate and manage language learning and teaching business. While in 1980's teacher talk is only seen as the source of comprehensible input for learners (Krashen, 1985) and studied separately by interactionist SLA researchers (Swain, 1995), the rise of communicative language teaching and acknowledgement of interactional competence (Young, 1999) as an unavoidable aspect of language competence give researchers the understanding that teacher talk and interaction in the classroom go hand in hand and inseparable constructs to research classroom (Hall, 2000; Hall \& Walsh, 2002; Seedhouse, 2004). For example, while teacher talk time is said to exceed student talk time (Chaudron, 1988; Cook, 2013) and this is always regarded as a negative aspect, different and new conceptualization of teacher talk gives insights into the potential of teacher talk in creating space and facilitating language learning in the classroom (Walsh, 2002) moving beyond classical initiation-response-evaluation dialogue (Lee, 2007; Waring, 2009).

Especially, the ground-breaking work of Seedhouse (2004) on the interactional organization of language classroom changes the way of studying classroom discourse and put the interaction at the center via using Conversation Analytic research methods. His work shows that the pedagogical and interactional factors operate together in unfolding classroom talk and constitute the classroom interaction fostering and facilitating language learning. Past research on language classrooms displays that only one-third of all talk in classes is student talk (Chaudron, 1988; Cook, 2013) and extended student talk in language classes is unfortunately rare (Juzwik, Borsheim-Black, Caughlan, \& Heintz, 2013; Swain \& Carrol, 1987); Seedhouse (2004) claims that the classroom has a distinctive pedagogic and interactional architecture and each classroom context (form and accuracy, meaning and fluency, procedural and task oriented contexts) involves different sequential organization of classroom talk. Parallel to that, each context naturally involves different amount of teacher and student talk. Thus, instead of focusing on amount of student talk as a separate construct, the unfolding and situated nature of classroom 
interaction and participants' orientation to learning in interaction are being extensively analyzed by socio-interactionist classroom discourse research.

One of the agendas of this line of classroom research is to study teacher talk and to unearth the facilitative and supportive classroom environment in which students participate and talk more. A growing number of conversation analytic studies focus on learners who take initiative to participate (Garton, 2012; Jacknick, 2011; Waring, 2011) and facilitative teacher talk that encourages learners to participate and speak more (Girgin \& Brandt, 2019; Sert, 2015, 2017; Walsh, 2002), and conversation analytic studies bring concrete interactional evidence from classroom interaction in different contexts.

In Turkish higher education context, there are a few Conversation Analytic studies focusing on classroom interaction and student talk (but see Can-Daşkın, 2015; CanDaşkın \& Hatipoğlu, 2019; Duran, 2017). However, there is a burning need for classroom research studies that demonstrate what is really happening in the classroom. Recent study (British Council-TEPAV, 2015), conducted in 38 universities across 15 cities in Turkey with the cooperation of the Ministry of Education, British Council and the Economic Policy Research Foundation (TEPAV) claimed that English as a Foreign Language (henceforth EFL) instructors working at the tertiary level do not employ student-student interaction, therefore students do not reach a higher level of performance in speaking and do not sufficiently partake in tasks like classroom discussions and debates, which also require extended student talk.

The present study, therefore, tries to examine one Turkish EFL teacher's actions to elicit extended student talk in a Listening and Speaking course at tertiary level in Turkish context. It aims to uncover the situations in which task progressivity and thereby extended student talk were promoted in an EFL context in a teacher-led whole class interaction in meaning and fluency contexts. Our main goal is to show an emerging interactional pattern involving longer student engagement and interaction when the teacher targets meaning and fluency. To achieve this aim, the following research question has led the study:

How does an EFL teacher promote and maintain extended student talk in meaning and fluency contexts in an EFL Listening and Speaking course?

\subsection{Literature review}

There is an increasing interest in classroom discourse in the field of foreign language teaching and learning to understand the interactional dynamics of a language classroom (Gardner, 2013; Huth, 2011). Based on the understanding that interaction is in the center of learning and teaching business in an instructional setting (Seedhouse, 2004), actions of the participants to manage and maintain the interaction are seen as achievements leading to successful practices of teaching and learning (Walsh, 2006). 
Conversation analysis (CA) is used to analyze naturally occurring spoken interaction (Seedhouse, 2005). It basically looks at talk-in interaction without any external theory and explore how participants interact with each other and what they collaboratively achieve in interaction through turn-taking, repair, adjacency pairs and preference organization (Seedhouse, 2005). As CA is solely concerned with what is observable in interaction (Seedhouse, 2005), participants' own actions such as taking turns and initiating repairs in an unfolding interaction bring evidence to their own interactional agendas. In an instructional setting such as classrooms having a specific institutional goal, conversation analysis shows how the teachers and learners carry out the interactional work of the teaching and learning in that specific context. Adopting an emic perspective, this systematic and rigorous research method provides sequential account of the participants' orientations and actions to participate and facilitate classroom interaction. Thus, CA is currently being employed in many fields of applied linguistics and teacher education such as CA for second language acquisition (Markee \& Kasper, 2004), language learning in classroom interaction (Seedhouse, 2004), language learning outside the classroom (Eskildsen, 2018), language teachers' interactional actions to facilitate language learning in the classroom (Sert, 2015; Walsh, 2002; Waring, 2016).

Contingent nature of classroom interaction involving co-constructed talk by participants create valuable learning space for students (Lee, 2010). The task of the language teacher is to orchestrate and manage unfolding classroom interaction and generate more learning opportunities for learners. Pedagogical goals of the language teacher and dynamics of classroom interaction are interconnected and operate together and, as a result, they form emerging classroom contexts (Seedhouse, 2004). For instance, in meaning and fluency contexts, the main aim is "maximizing opportunities for interaction" (Seedhouse, 2004, p. 111) and "promoting extended learner turns" (Sert, 2015, p. 137) (please see Seedhouse (2004) for other contexts). Following Seedhouse (2004), Walsh (2006) puts forward the framework of classroom interactional competence (CIC, hereafter) and defines it as "teachers' and learners' ability to use interaction as a tool for mediating and assisting learning” (p. 132). Eliciting extended student talk is one of the highlights of CIC referring to opening space for learners to produce language which is observable evidence of language learning. Walsh defines extended learner turn as "learner turn of more than one clause" (Walsh, 2006, p. 67). Walsh (2012) identifies promoting extended student turn as teachers-must-do practices in language classes if they want to successfully create space for learning. To this end, teachers may use increasing wait time; resisting the temptation to fill in silence- in other words, reducing teacher echo; allowing planning time; lack of teacher repair; signposting in instruction; seeking clarification and shaping learner contributions.

Follow-up micro-analytic studies in the Turkish higher education context are also conducted and additional resources such as effective use of board and use of translation are found out as teachers' ways of shaping learner contributions (CanDaşkın, 2015). Girgin and Brandt (2019) show that minimal response tokens in 
teacher third turns have potential to create space for further learners' turns. In brief, the framework of CIC conveys the idea that language teachers perform immense interactional work to sustain and promote extended learner talk to co-construct learning-conducive interaction with learners.

In addition to interactional resources listed above, it is obvious that effective questioning elicits learner talk. Teacher questions were first studied by Mehan (1979) in classrooms adding the distinction between known information questions (display questions) vs. information seeking questions (referential questions) to the classroom research literature, and he (1979) also unearthed the sequential organization of IRE (Initiation-Response- Evaluation) which is extensively used in teacher led classrooms. Although this triadic dialogue seems to restrict student talk, the conversation analytic studies (Hellerman, 2003; Lee, 2007; Park, 2014; Waring, 2008) highlight the fact that evaluation turns can be used as follow-ups to open space for eliciting learner talk. In other words, the evaluation turn does not necessarily give feedback and close the case. On the contrary, language teachers are advised to withhold the evaluation turn (Waring, 2008; Wong \& Waring, 2009) and keep contingent questioning. Thus, questions can be asked both in initiation move (I) and in the third move in IRE sequence.

While sequential position of the questions is important, the types of questions are also analyzed to see their potential for eliciting student talk. Micro-analytic analyses of different types of questions show that every single question serves a role in an unfolding classroom interaction. While Walsh (2006) claims that asking information seeking questions is one of the ways to get learner talk, various instructive and interactional functions of known-information questions (display questions) are described and regarded as building blocks of classroom interaction, thereby named as "situated accomplishments" (Lee, 2006, p. 706) in unfolding classroom interaction. As long as the questions have been built on what students have previously produced, they can promote longer, sustained student talk demonstrated by many conversation analytic studies highlighting the potential of teachers' follow-up turns to open space for more talk (Lee, 2007; Walsh, 2006).

In classroom discourse, teachers and students employ different kinds of questions to achieve different interactional and pedagogical aims (Bozbiylk, 2017; Koshik, 2002a, 2002b, 2003, 2005; Lee, 2006, 2008; Waring, 2012; Yüksel, 2014). Lee (2008) studied yes/no questions in a teacher led ESL classroom in a university setting which showed that they serve many functions such as building next turns in interaction and understanding what students know at that moment of interaction. In writing tutoring contexts, designedly incomplete utterances (DIU) are used by teachers to get students self-correct (Koshik, 2002a) and yes/ no questions to show troublesome parts in writing and designed as reverse assertion to criticize student's performance (Koshik, 2002b). On the other hand, alternative questions require the interactants to choose one of the options available in the question. For example: "A: Shall we go by BÚS or TRÀIN? B: By BÙS” (Quirk \& Greenbaum, 1973 as cited in Koshik, 2005, p. 194). Therefore, alternative questions limit the upcoming answers to one of the alternatives 
available in the question (Hayano, 2013) and projecting one-word answers from the next speaker.

In Turkish instructional context, Bozbiylk's micro-analytic study of teacher trainees' questioning practices in a high school setting (2017) demonstrated that the employment of different types of questions such as wh-questions, DIUs, alternative questions and yes-no declaratives /interrogatives in specific sequential positions was found to be a facilitative interactional resource aiming extended learner turns in meaning and fluency contexts. In a Turkish university setting, Can-Daşkın (2015) explicated the use of elaboration questions that are used to shape learner contributions and promote more responses from learners in the next turns in the same context. The reviewed studies underlie the fact that sequentially appropriate and relevant questions stimulate learners' involvement and longer turns in unfolding classroom interaction when teachers establish meaning and fluency contexts. In other words, rather than the type of the questions, employment of different questions inserted in appropriate positions in unfolding interaction keep classroom interaction flow and lead learning opportunities.

All in all, with regard to the teacher practices in an unfolding classroom interaction, it is seen that language teachers accomplish many interactional tasks by withholding and/ or elaborating on their turns, inserting questions in specific interactional phases, making on-the-spot decisions and thereby enriching IRF pattern by such interactional and pedagogical moves. Considering the emergent nature of classroom interaction, the present study tries to explore one EFL Listening and Speaking classroom in a university setting in Turkey and an EFL teacher's practices to elicit extended student turns in meaning and fluency contexts.

\section{Method}

This study employs conversation analysis as a research method to examine an EFL teacher's actions to elicit sustained student talk in a freshman class in university setting. Conversation analysis is the systematic analysis of talk in interaction coconstructed by people in their everyday lives (Hutchby \& Wooffitt, 1998). Adopting an emic perspective, it is based on the principle that there is order and organization in talk. Analyzing preference, turn taking and repair organization of the interaction, conversation analysis examines participants' actions and achievement in interaction. In instructional settings such as language classrooms, CA "enables researchers to reveal how practices of teaching and learning emerge and are co-constructed in talkin-interaction" (Sert, 2017, p. 16). To this end, micro details of the talk (overlaps, silences, turns, intonation and stress patterns and embodied conduct) are transcribed using a transcription convention (Jefferson, 2004). And then, the transcribed data is analyzed to see what participants say and do in interaction. Since CA is based on an emic perspective, the participant's next turn in an unfolding interaction shows his/ her understanding and interpretation of the previous turn which is called next turn proof procedure (Seedhouse, 2005). This procedure based on the participants' own 
orientations in interaction (Seedhouse, 2005) helps analysts to ensure validity of the analysis.

\subsection{Participants}

The study was conducted in a private university in one of the central cities of Turkey. The participants were one instructor and 14 EFL freshman computer engineering students. The instructor was a graduate of a faculty of letters. She received her teaching certificate in the undergraduate level and attended in-service teacher training programs in her first two years of teaching. She had four yearteaching experience. She taught English to freshman students at the department of computer engineering. They had a 10 hour-intensive English program. The department offered three hours a week course to improve students' listening and speaking skills. They were using B1 level materials for the course in which the data were collected. They were regarded as pre-intermediate learners of English.

\subsection{Data collection}

In order to gather data for the present study, an EFL class was audio-recorded for nine classroom hours, varying from 35 minutes to 45 minutes in each session over five weeks, which was equivalent to one third of the spring semester of the academic year. After talking to the instructor, receiving her and learners' consent for the study and getting permission from the institution, the researcher (one of the authors) started to collect the data. In the first week of data collection, she used one recording device, in the second week she started to use two audio-recording devices, replaced one on the teacher desk and the other on the back side of the class to minimize incomprehensible voices as much as possible.

\subsection{Data analysis}

The audio recordings were transcribed following the Jeffersonian transcription system (Jefferson, 2004). Nine classroom hours of data were roughly transcribed first and episodes involving extended learner turns in pre and post listening tasks were transcribed in detail (including silences, intonation patterns). From the emic perspective of conversation analysis, learners' involvement in speaking activities manifesting itself via sequentially relevant and extended learner turns ensures the progressivity of the tasks and the lesson. Those episodes where the teacher targets meaning and fluency and maintains task progressivity were added to the collection and researchers attempt to unearth teacher practices to promote and maintain student talk in the series of speaking tasks.

\section{Results}

The classroom interaction involving meaning and fluency contexts demonstrates that the teacher facilitates and scaffolds learners to produce extended talk through 
various interactional resources. As a way to enhance learners' participation, she gives students time to get prepared for the upcoming speaking task which will be presented in the following sub-section (Section 3.1.). This is one of the distinctive ways to maintain task progressivity, thereby eliciting extended learner turns. In the second sub-section (Section 3.2), a recurring interactional pattern will be presented: the teacher employs alternative questions as a sequence opener, she inserts elaboration questions to maintain student talk, she provides candidate words when students request help, and finally she initiates minimal response tokens, thereby withholding evaluation turn. The following two sections will demonstrate teacher actions that elicit extended learner turns in pre- or post-listening tasks and achieve task progressivity and goals of the specific context.

\subsection{Providing planning time}

The following extract presents an example of a specific teacher action to maintain the task progressivity. The learners are able to participate in the task and the teacher elicits sustained learner turns thanks to the on-the-spot decision in the flow of interaction.

This extract showcases a pre-listening task in which learners were instructed to brainstorm about the advantages and disadvantages of nuclear energy in pairs as the learners would listen to a debate about the same topic in the subsequent listening task. This episode was recorded towards the end of the lesson of the first week. Since all the data came from the same classroom, for all the excerpts analyzed $t$ stands for the teacher, LL refers to the learners in chorus and s1, s2, and s3... represent the particular students in the classroom.

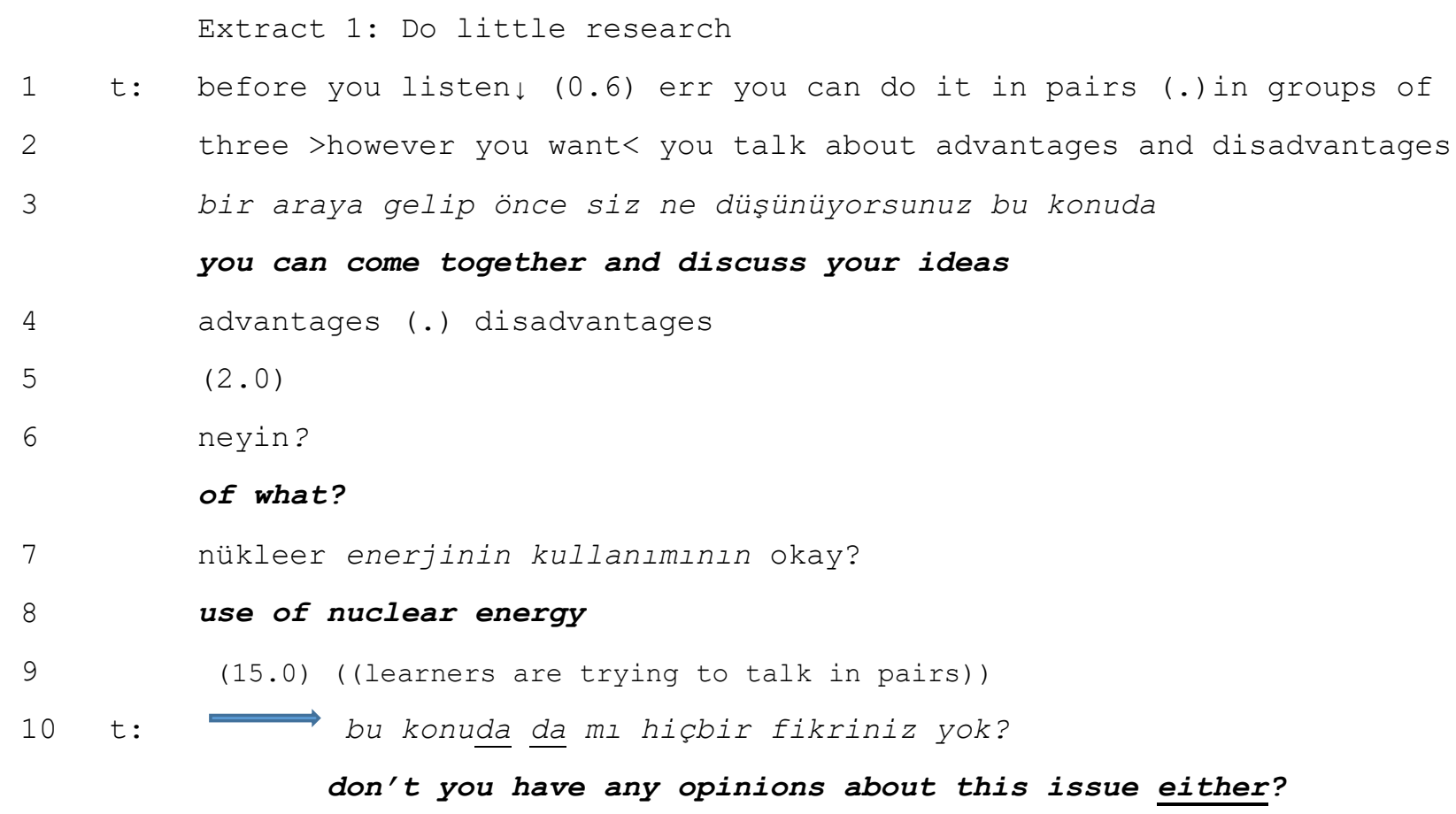




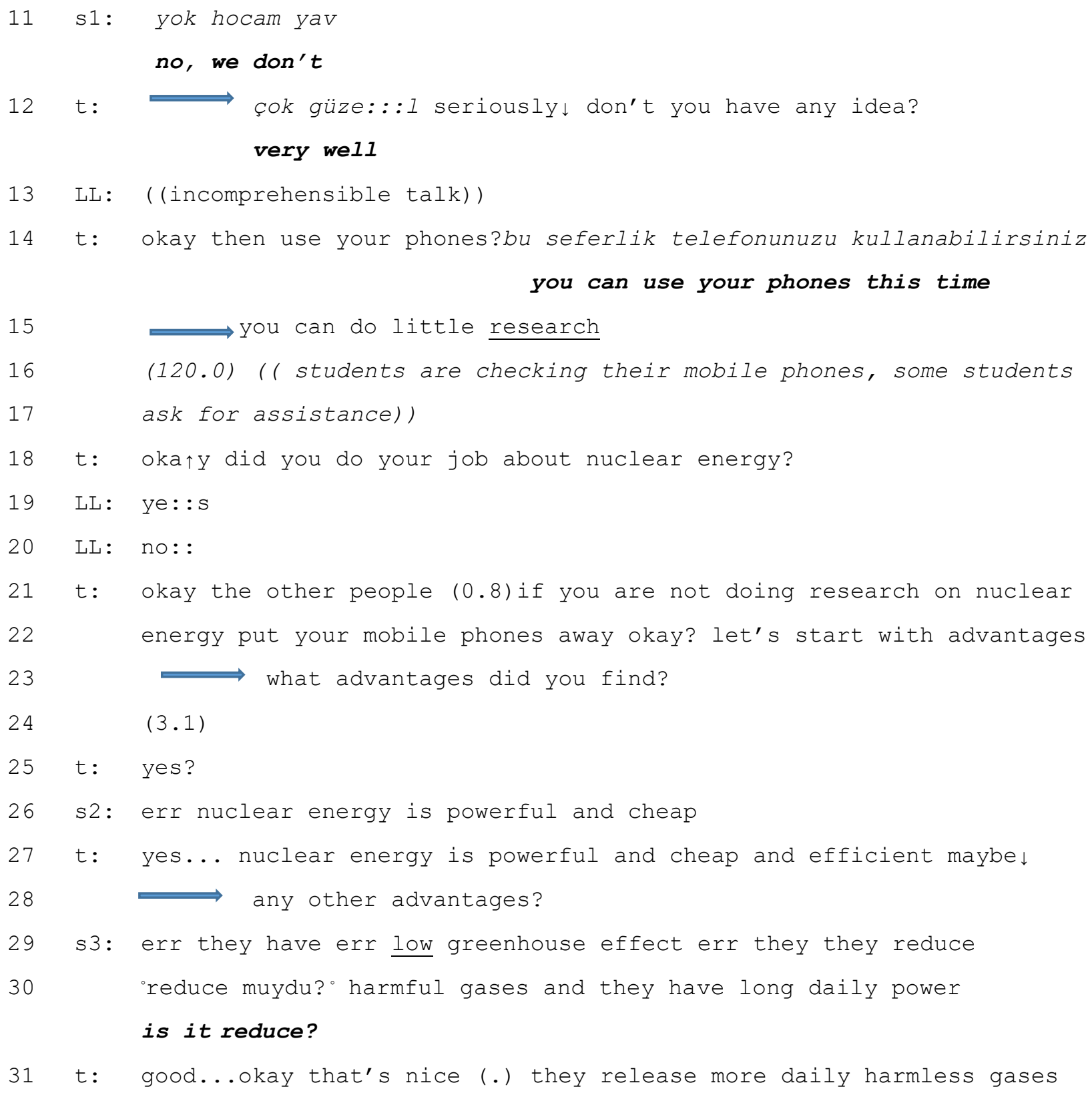

In the first line, she gives the instruction underlying that the task is pre-listening. After 0.6 seconds of silence, she continues to give rules about the way students talk and then she gives the topic. In line 3 , she switches the language and uses Turkish as a multilingual resource to repeat the instruction. In line 4, she switches back to English and finishes her instruction and gives the topic of the discussion. After 2 seconds of silence (5), the teacher initiates comprehension check question in Turkish and gives the answer herself (7) which may show that that is not a question that projects an answer from the class. It could be an expansion to strengthen the clarity of the instruction." However, students' world knowledge is not sufficient enough to participate in interaction as it is inferred from her initiation in line 10. Although students' utterances are not comprehensible in the recording, the instructor's 
initiation "bu konuda da mı hiçbir fikriniz yok- don't you have any opinions about this issue either?" demonstrates that instructor's understanding that students do not have sufficient knowledge about the topic to be discussed. Designed as a reversed polarity question (negative yes/no question) (Koshik, 2002b), this question functions as Epistemic Status Check (ESC) (Sert, 2013) which helps the teacher to interpret students' epistemic stance. In line 11, s1 displays his insufficient knowledge. In the following turn (12), the teacher re-initiates an epistemic status check in a similar question design (don't you have any idea?) in the target language. It is evident from her next turn (14), students maintain that they do not have any ideas. At this point the interaction is blocked because the task itself is unable to drive students to talk. To handle this breakdown, the teacher suggests learners to use their mobile phones to do research about the topic (14-15). Including mobile phones as an external instructional resource to gather new ideas for the upcoming brainstorming task, the teacher opens learning space in the classroom and gives learners time to get prepared for the interaction. During two minutes, students check their mobile phones and some of them ask for assistance (16). In line 18, the teacher checks whether students are ready to participate. While some say yes, some of them indicate they are not ready yet. Still, in line 21, the teacher wants students to put away their mobile phones and announces the start of the task. She asks for the advantages of the nuclear energy and initiates it with wh- question design which enables her to "steer learners into particular directions" (Lee, 2007, p. 1215) in line 23. After waiting for 3.1 seconds, the teacher gives the turn to s2 by saying yes (25). After a hesitation marker, s2 shares his finding (26). In the next line, the teacher initiates confirmation of this finding, repeats s2's utterance and adds another adjective efficient to summarize s2's opinion. In line 28, she asks for "any other advantages" and this time a longer answer comes from s3 without any waiting time. S3 adds to the advantages of the nuclear energy. Although s3 starts with hesitance marker and requests help for the word reduce (line 29), he maintains his talk. In the following line, the teacher initiates Explicit Positive Assessment (hereafter EPA, Waring, 2009). She paraphrases what s3 utters in the previous line.

This extract showcases the teacher's complementary interactional actions to maintain task progressivity, thereby eliciting sequentially relevant and extended learner turns. The teacher's on the spot decision for providing planning time for students clearly opens space for learners to participate in the speaking task (Line 15). Directing learners to their mobile phones as an external resource enables learners to gather information and participate in the task by sharing their findings (Lines 14-15). Moreover, steering the discourse by first asking the advantages of the nuclear energy (23) helps learners navigate the interaction and find a way to participate more. As a result, the teacher achieves her pedagogical goal and elicits many learners' turns on the nuclear energy and prepares them for the upcoming listening task. In addition to providing planning time, the teacher follows an interactional path to elicit students' extended talk which will be presented in the next section. 


\subsection{Interactional unfolding of eliciting and maintaining extended student talk}

A major institutional goal of the teaching business is to maintain the progressivity of the series of tasks which shape the lesson. In addition to giving preparation time for students, employment of different types of questions in specific sequential positions enable learners produce extended turns. After ensuring students participation, the teacher also needs to keep learners speak and share their opinions more to maintain the speaking tasks. The micro-analytic analysis of the EFL classroom interaction showed that the participants follow an interactional pattern which involves extended learner turns. The following extracts will be presented to unearth this unfolding interactional pattern followed by the participants of the listening and speaking course.

The extract 2 from the fourth week of the term displays this distinctive interactional pattern which elicits and maintains student talk. In Extract 2, the class is doing a small post-listening speaking task. The listening is about alternative treatments. Out of four advertisements for alternative treatment which are meditation, aloe vera, aromatherapy and acupuncture, learners are asked which one they would like to try after viewing the advertisement.

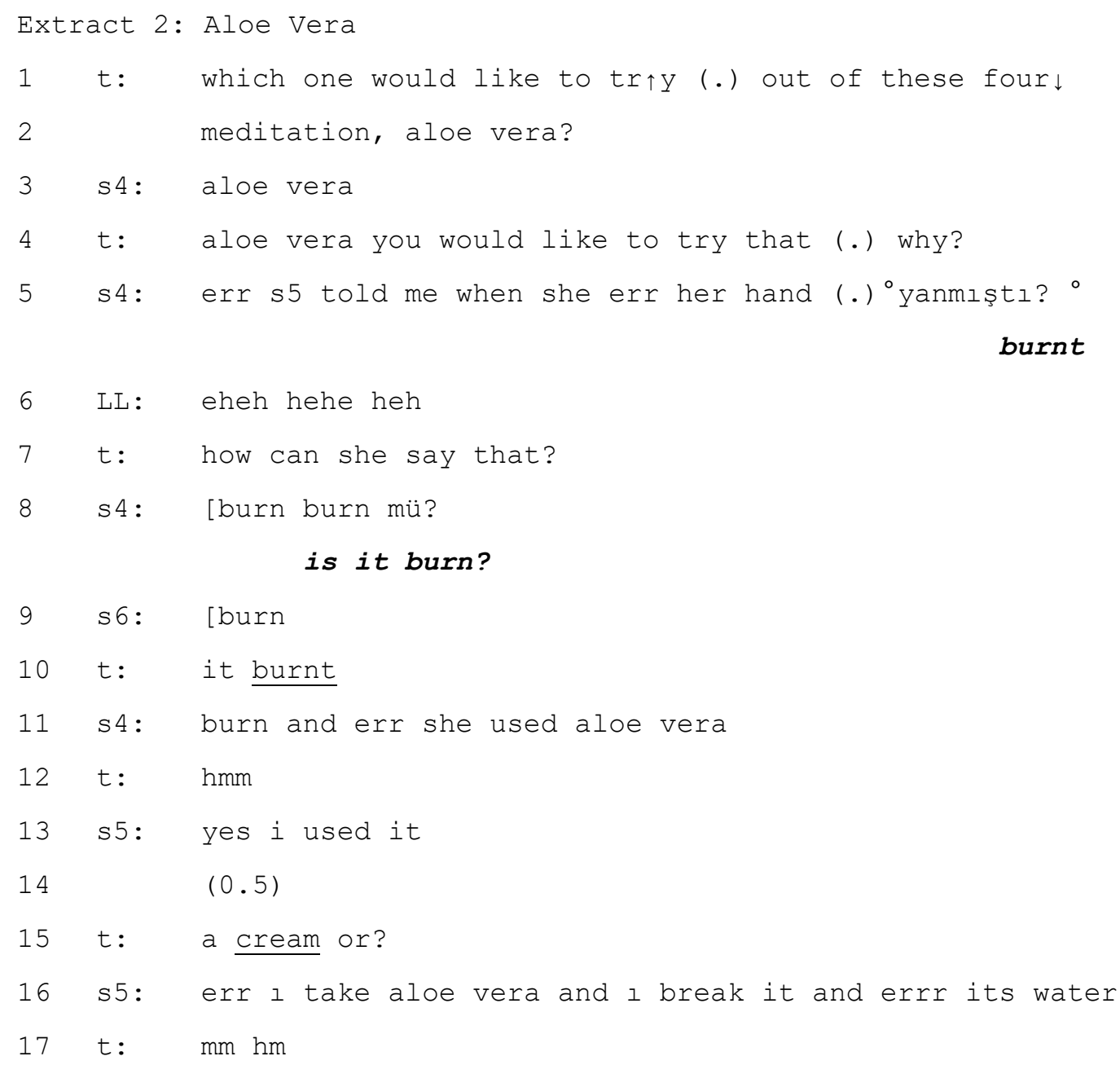




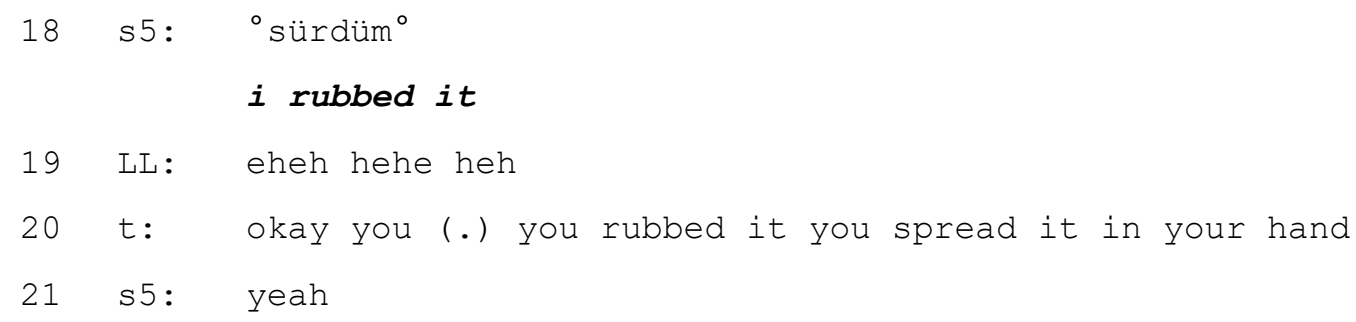

After asking the kind of treatment learners would choose which is designed as an alternative question (meditation vs. aloe vera line 2) (Koshik, 2005), the teacher elicits a one-word answer "aloe vera" (3) from s4. In the subsequent line which is a clear feedback (F) turn, teacher does many actions: she echoes s4's answer, extends the students' answer (you would like to try that) as a way of scaffolding (Walsh, 2011) and after a short pause she initiates an elaboration question (Can-Daşkın, 2015) in line 4. By withholding evaluation and inserting post-expansion sequence via an elaboration question, the instructor expands the scope of the task and maintains the participation of s4. In line 5, the student tries to explain the reason why she would choose aloe vera through extended talk by giving a reference to her friend (s5) who is also part of the story. In the same line, at first the student tries to complete her sentence but she is not able to find the English equivalence of "yanmıştı" in the first trial and asks for help in Turkish in a quieter tone which starts a word search sequence. Laughter comes from class following s4's use of the Turkish word, which displays her misalignment with the L2 only micro-policy (Amir, 2013) of the class. In order to re-establish the order, the teacher invites other class members to find the word by saying "how can she say that" in line 7 . In the following turn, s4 takes the turn and wants to check her candidate word burn she remembers and offers the word in the form of a request for verification. In line 10, the teacher initiates form focused repair and uses the candidate verb in past form. S4 does not take up the repair and repeats the word and continues talking referring to her friend's experience with one of the ways of alternative treatment in line 11 . In line 12 , the instructor initiates a minimal response token $(\mathrm{hmm})$ which is a clear evidence of her listenership. This token functions as a continuer to withhold third turn evaluation of the teacher (Girgin \& Brandt, 2019) and apparently encourages s5 to participate and continue to provide the account as the unfolding interaction shows. In line 13, she takes the turn without being invited and confirms her classmate's account. After 0.5 seconds of silence, the teacher initiates another question "a cream or?" but leaving the second alternative as Designedly Incomplete Utterance (DIU, Koshik, 2002a) this time. In the next turn, it is seen that s5 interprets this question as somehow clarification request and elaborates on her experience in line 16. She initiates repair and offers the word water to repair cream uttered by the teacher in the previous turn. In line 17 , the teacher initiates a minimal response token to demonstrate her listenership. In the subsequent turn, s5 says sürdüm (I rubbed it) in Turkish in a quiet tone which is followed by laughter from the class again. In line 20, the teacher initiates acknowledgement token and again shapes the learner's Turkish contribution by translating and extending the 
answer. This turn is also an example of scaffolding described by Walsh (2011) and feedback turn. In line 21, the student accepts the feedback and confirms the teacher's translation.

As it is evident from the flowing interaction, there is an interactional path followed by both students and the teacher. The questions designed and inserted in various sequential positions (lines 1-2, 4, 15), addressing students' emergent knowledge gaps and word searches (lines 10,20), and withholding the evaluation turn via minimal response tokens (lines 12,17) open space for interaction and elicit many turns from the students. In addition to question design and minimal response token to postpone evaluation turn, the teacher provides feedback to students via shaping their contribution (lines 4,20 ) by extending their answers. In sum, these interactional moves enhance students' participation, stimulate sequentially relevant and appropriate responses and extended turns which fulfil the goals of the meaning and fluency context and thereby ensuring task progressivity.

With regard to the question design, alternative questions are observed to be employed by the teacher as an interactional resource to get one-word answer in a sequence opening position (line 1). The teacher provides learners with choices and wants them to choose one option. She utters each option in the same tone of voice without emphasizing one more which makes the question alternative (Koshik, 2005). After eliciting a one-word answer, she requests them to justify and explain their choices in the post-expansion sequence with the help of elaboration questions designed in wh- formats.

The extracts below (Extracts 3, 4 and 5) taken from the same lesson in the third week represent a single case and each one showcases the sequences of the distinctive interactional path shown in the extract 2 . In those successive extracts, the instructor tries to warm-up the class for an upcoming healthy food-oriented listening task. Prior to the extract 3 , the teacher shows four different pictures in the course book depicting people having different life styles. The teacher requests learners to look at the pictures and talk about the differences between the life styles of the people in the picture. After getting an answer about an unsocial boy playing with his computers, the teacher opens a new sequence in line 21 . In the extract 3 , the teacher opens the sequence by an alternative question and this extract demonstrates the teacher's interactional actions to elicit one-word answer from the class.

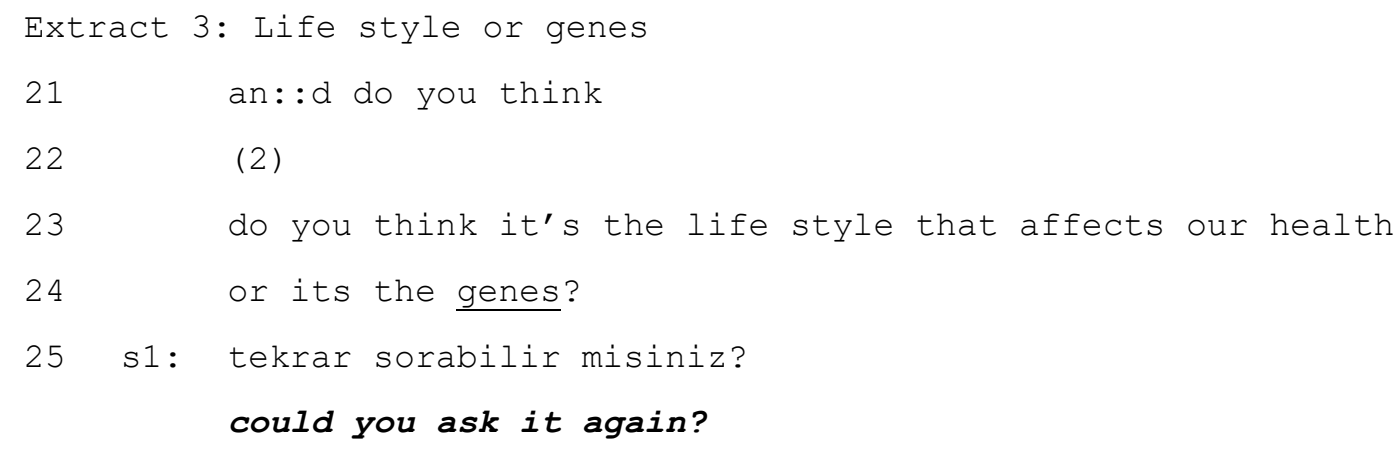




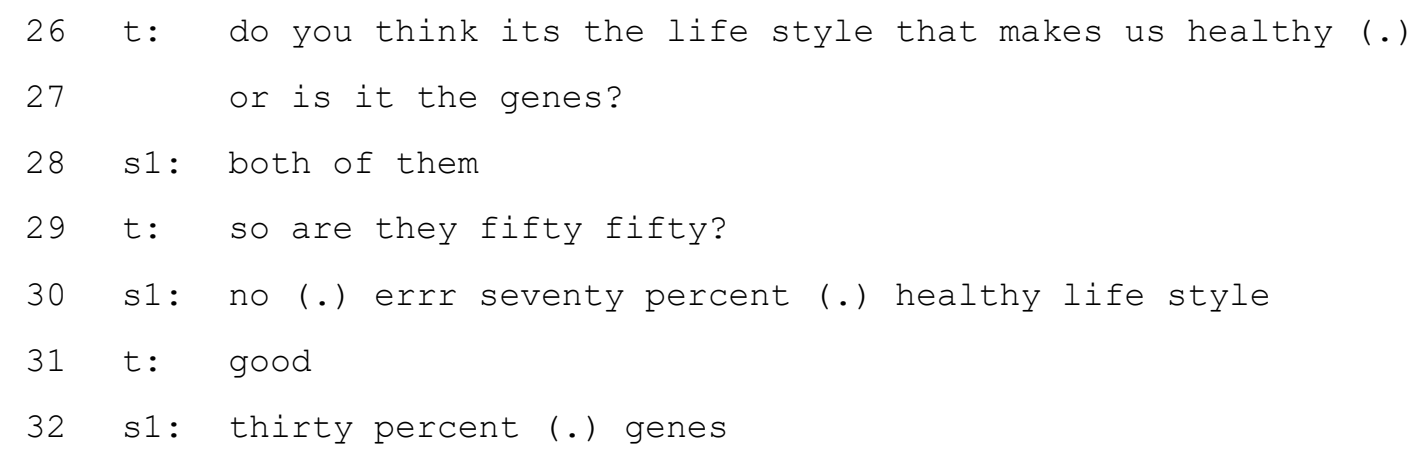

In line 21, the teacher opens a new sequence by asking do you think but she does not complete her turn. After 2 seconds of silence, she re-opens a new sequence with an alternative question. She offers learners two options (life style or genes) and wants them to choose one option that would affect people's life style. She puts additional stress on the latter option, genes which provides evidence that the teacher wants to shift the topic and talk about the genes. She starts her question in yes/ no interrogative (do you think) and then provides two alternatives to choose (lines 23-24). With the help of this embedded alternative questions (Koshik, 2005) she manages to navigate the classroom discourse and change the topic. In line 25, in Turkish s1 wants the teacher to repeat her question. Upon this request, the teacher reformulates her question (26-27) and elicits an answer (28). In line 29, as a post-expansion, the teacher initiates a confirmation request in a yes /no interrogative format to see whether options have the same importance for a healthy life. In line 30, s1 says no and explains his opinion. As a follow up, the teacher says good which might have closed the sequence acting as an evaluation turn, however; s1's next turn shows that this is not an evaluation turn. S1 reconfirms what he has said in line 30 and closes the sequence.

In this first phase of this single case, alternative question is used as a sequence opener (lines 23-24). After clarification request (line 25), the student gives an answer choosing two alternatives. Then, in line 29 , the teacher initiates a clarification request and $\mathrm{s} 1$ gives sequentially relevant response which maintains the task.

The following extract demonstrates the rest of the interaction presented in the extract 3. After getting the answer that genes may affect people's life styles, the teacher continues asking questions.

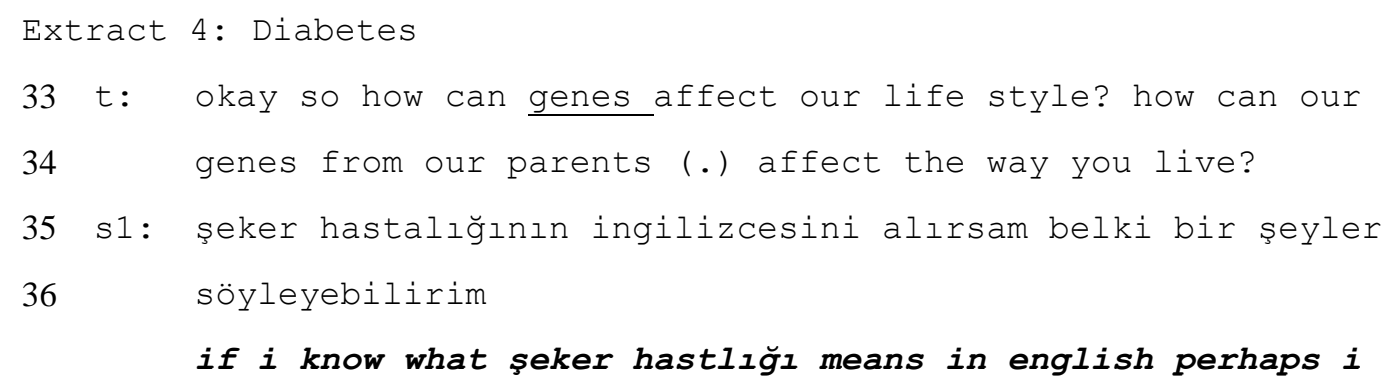


can say a few words

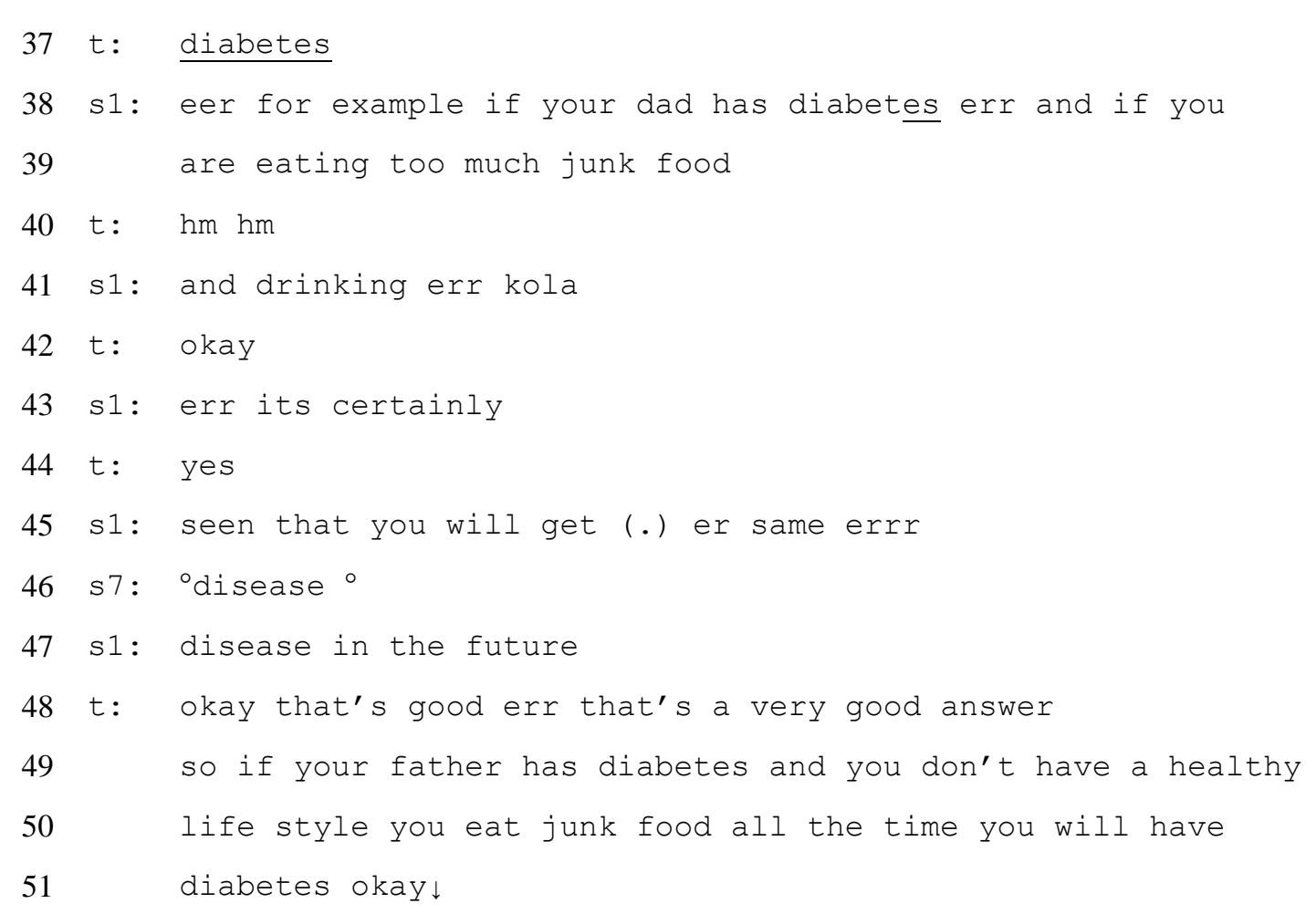

In line 33, the teacher asks an elaboration question after eliciting the answer from s1 that genes may affect people's life style. She reformulates her question in the following line (34) and s1 requests help from the teacher as he does not know the key word to continue (35-36). In line 37, the teacher provides the word diabetes. After this scaffolding move, s1 manages to express his opinion and exemplifies the way genes affect people's life style (38-39). The teacher utters minimal response token to show her listenership and get the student continue to speak (line 40). In the following line, the student continues to contribute and teacher utters okay as a go-ahead response (42). The student keeps continuing his utterance (43) and teacher initiates another go ahead response (44). In line 45, s1 hesitates to speak and one of his classmates (s7) offers him a candidate word in the next line (46) and s1 accepts this candidate word and goes on speaking. In line 48, the teacher first gives EPA and then provides summative closing statement (Park, 2012) to summarize s1's contribution.

In this extract, as a follow up to the extract 3, the teacher uses elaboration question, addresses student's request for help and keep initiating go ahead responses promote learner participation and consecutive turns.

After the summative closing statement (lines 49-51), s1 utters obezite in a lower tone of voice. The teacher orients to this contribution and the interaction continues. 


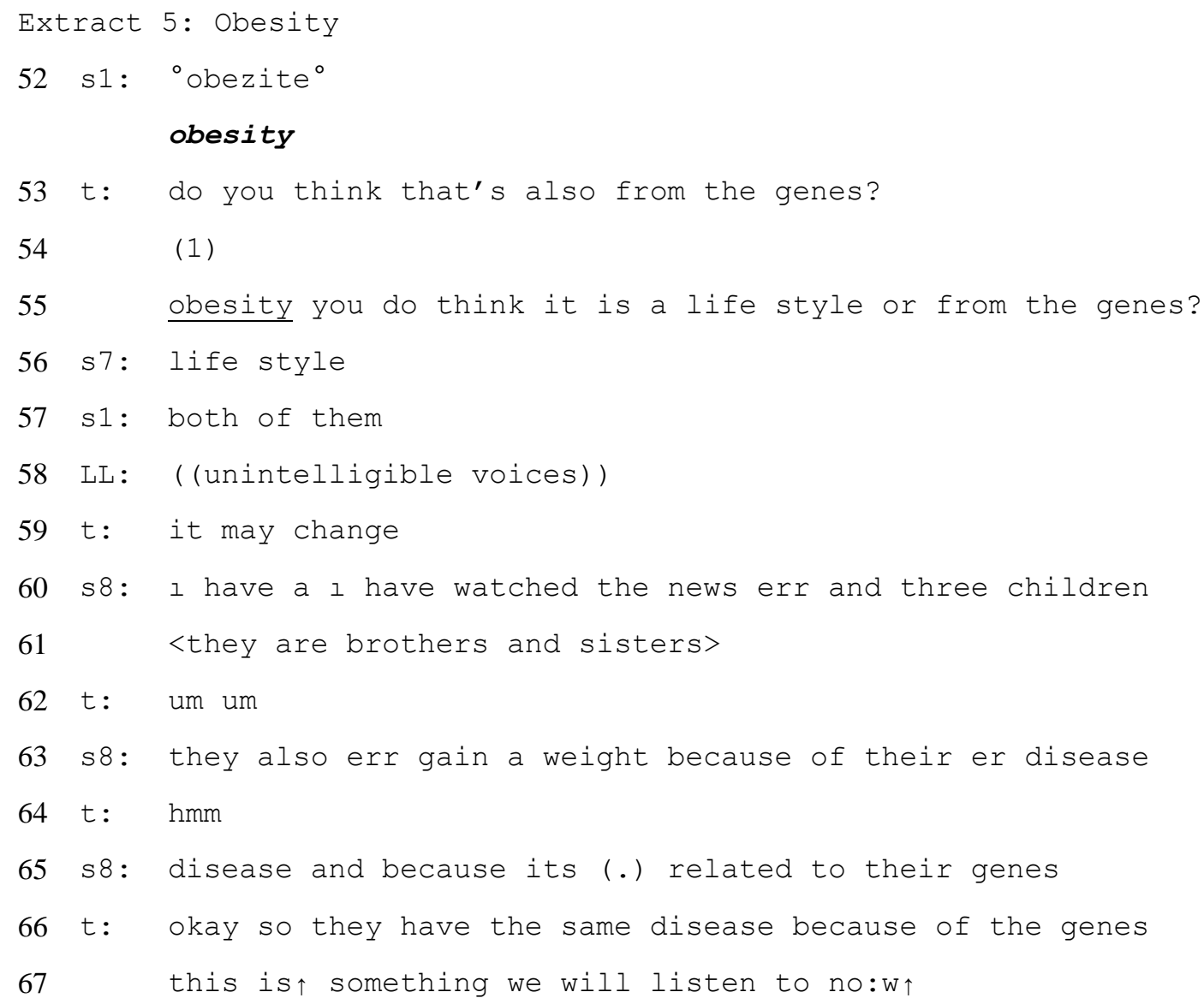

After the summative closing statement (lines 49-51), s1 says obezite in Turkish (obesity in English) in a quieter tone (52). In line 53, the teacher takes up what 1 has said and builds on it by asking the reason for obesity. After one second of silence, she puts emphasis on obesity and initiates an alternative question (55) which invites learners to make a choice. S7 says life style (56) and after unintelligible voices to the researchers, the teacher says it may change (59) which might have closed the topic. However, s8 gets the turn and refers to the news she has watched. Uttering minimal response tokens (line 62) the teacher shows that she wants her to continue to talk. In line 63 , s8 keeps talking about the family in the news. Similarly, the teacher only initiates $\mathrm{hm}$ which keeps $\mathrm{s} 8$ to progress. It is clear that $\mathrm{s} 8$ contributes with extended talk to the interaction. In line 66 , she paraphrases what s8 has said and closes the sequence announcing the upcoming listening task.

Extracts 2, 3, 4, and 5 demonstrate a piece of classroom interaction discourse in which the participants manage task progressivity through sequentially relevant questions and answers. As these extracts vividly represent, the micro-analysis of the classroom interaction data shows an emerging particular interactional path followed by the participants. This systematically organized interactional path enables task progressivity and promotes learners' extended turns. The recurring interactional moves form an interactional pattern as Table 1 displays. 
Table 1. Order of the interactional path emerged in the data

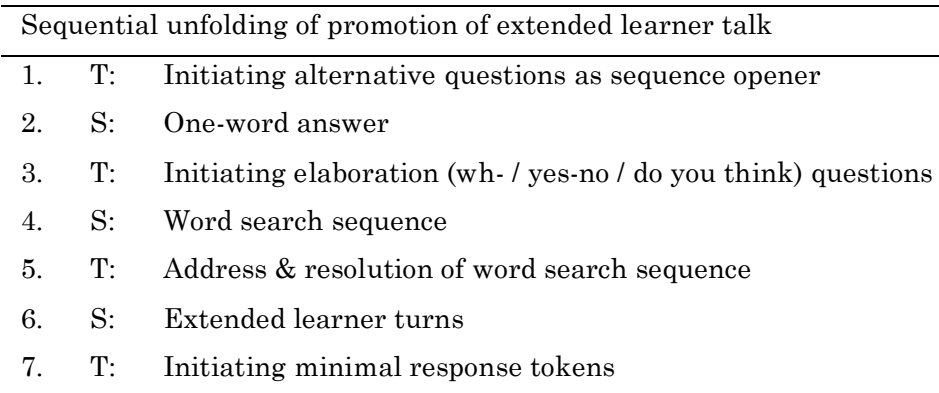

In the data, the teacher employs alternative questions as a sequence opener (Ex. 2, line 1; Ex. 3, line 23; Ex. 5, line 55). This type of question projects one-word answer from the students. Although the study does not compare the other types of questions initiated in the pre-sequence and the data yield interactional evidence of the effect of this type of question on learners' participation; it is clear that learners take the turn and give one-word answer as a second pair part (Ex. 2, line 3; Ex. 3, line 28; Ex. 5, line 56). In other words, the teacher may use this question design to invite learner oneword utterance in the first place.

After getting one-word answers, the teacher starts her elaboration questions designed as wh- type to get extended learner talk. Students usually talk about their choices and justify their decisions via their experiences (Ex. 2: aloe vera) or the evidence from the world (Ex. 5: obesity). In those sequence expansions, the teacher withholds evaluation turn and initiates minimal response tokens (hm, um) to show that she is listening and maintain student talk. Even if she initiates good (Ex. 3, line 31) or very good answer (Ex. 4, line 48) which could have been interpreted as Explicit Positive Assessment (Waring, 2009), those initiations do not close the sequence; instead, they maintain interactional flow as similarly presented in Fagan's (2014) study and accomplish progressivity of the lesson (Margutti \& Drew, 2014).

In the case of emergent knowledge gaps (Ex. 2, yanmıştı line 5); (Ex. 4, şeker hastalığ line 35$)$ the teacher's directly providing candidate words or inviting other members of the class (Ex. 2, how can she say that? line7) helps learners continue to participate in interaction and speak more. In extract 4, peer help from another student without any invitation (disease line 46) shows that students are able to cooperate to resolve knowledge gaps (Jakonen \& Morton, 2013) and thereby help others to maintain their turns and extended contribution. Moreover, teacher validates learner's responses (Waring, 2016) by addressing to them and asking further elaboration questions which lead to extended learner talk in the subsequent turns. To illustrate, the question why (Ex. 2, line 4), the confirmation request (Ex. 3, line 29) and another elaboration question (Ex. 5, line 52) validate the learners' previous responses and request more student elaboration.

In conclusion, teachers' enabling interactional resources promoted extended learner turns and built an interactional mosaic with teachers' complementary actions. This 
unfolding interactional mosaic interwoven with on-the-spot decisions, systemic use of questions, addressing word search sequences and initiating minimal tokens made extended learner turns possible and fulfilled the goals of the meaning and fluency context.

\section{Discussion and Conclusion}

The findings of the present study revealed that the teacher maintained and promoted student talk in meaning and fluency contexts by drawing on various interactional resources in a teacher-led EFL classroom at tertiary level. In order to enhance learners' participation and enable their active participation into a speaking task (Ex. 1: Do little research) she gave students planning time and directed them to their mobile phones as an instructional material after checking their epistemic status. As Walsh (2006) states "good teaching is concerned with more than good planning...teaching has two essential ingredients: planning and improvising. The interactive decisions taken by teachers while teaching is at least as important as the planning that occurs before teaching" (p. 19). In the current study, it was observed that the instructor had got these two vital features. By designing the task which had the potential to drive learners to speak for extended time, she had demonstrated her planning skills. By improvising at the moment of inhibited interaction due to the lack of student world knowledge on the speaking task topic, she improvised and asked learners to utilize another epistemic resource in the classroom, which was students' mobile phones (Ex. 1, line 14). In this way, she was able to enhance interaction, which was conducive to extended student talk. Similarly, Waring (2016) conceptualizes teaching as "being responsive to the moment" that is to say, that language teachers should both preserve the integrity of the moment and adjust shifting demands of the moment (p. 126). In other words, language teachers are expected to monitor learners' needs, lacks and find a way to address them and maintain pedagogical focus of the moment at the same time. As it is seen in Extract 1, the contingencies may occur and students are not able to execute the tasks as they did not have any ideas. While managing contingencies, the teacher produces ESCs to understand students' epistemic stance, and then provides planning time to collect more information to share. To manage contingencies and turn them into learning opportunities is the task of language teachers.

The classroom interaction data also revealed that the teacher followed a distinctive interactional path to promote and maintain extended student talk in meaning and fluency contexts (Table 1). This interactional path is a systematic sequential organization co-constructed by the participants and managed by the teacher. Drawing from the earlier micro-analytic studies in similar instructional contexts such as alternative questions (Bozbiyık, 2017), elaboration questions (Can-Daşkın, 2015), distinctive minimal response tokens (Girgin \& Brandt, 2019), and positive evaluations (Fagan, 2014; Margutti \& Drew, 2014), this study contributes to the classroom discourse literature presenting a sequential organization of extended learner talk through those interactional resources when the pedagogical focus is on meaning and 
fluency. The sequential unfolding of extended learner talk in meaning and fluency contexts involves alternative questions in the first pair part as a sequence opener. For instance, in extract 2 , the teacher asked students to choose one alternative treatment among four of them and listed meditation and aloe vera (line 2). Or in extract 5, the teacher clearly asked an alternative question "do you think it is a life style or from genes?" with two options (line 55). Without any wait time, students got the turn and voiced their choices. Via alternative questions, the teacher gave two or more options to the class and let them choose one. This question type was used as sequence opener and to promote learner participation since it gave learners options and requested them one-word answers.

After enabling learners' participation through alternative questions seeking oneword answers, the teacher employed wh- questions and yes/no questions to get students to elaborate and justify their answers (Ex. 2, lines 4 \& 22; Ex. 3, line 29). This is what Walsh (2006) suggested as "exploiting questions" that make the interaction authentic giving message that students are not contributing just for the sake of satisfying teacher. One of the components of Classroom Interactional Competence (CIC), opening interactional space is sustained by this contingent questioning such as do you think questions (Ex. 3, line 23; Ex. 5, line 53). Using contingent questioning validates learners' previous responses (Waring, 2016), the discourse is successfully woven by the teacher and authentic interaction environment is flourished where students contribute and share their opinions, stories and experiences through extended turns. All in all, the teacher contingent questioning directly serves the goals of meaning and fluency context and promotes extended turns from students (Seedhouse, 2004; Sert, 2015).

To keep eliciting more student talk and to maintain the progressivity, the teacher provided learners with candidate words (Ex. 2, line 10; Ex. 4, line 37) when they claimed insufficient knowledge (Ex. 4, line 35) (Sert, 2011) or invited other classroom members to solicit help (how can she say that? line 7) when the participating student initiated a word-search sequence in Turkish (Ex. 2, line 5). Sometimes, students took initiative and helped their friends to continue their talk by offering candidate words (Ex. 4, disease line 46). This collaborative and co-constructed work accomplished by learners and teacher helps interaction flow smoothly and fulfilled the pedagogical goals of the meaning and fluency context. The study reveals that other members of the classroom even if they are over hearers can participate in interaction and help their friends in the case of emergent knowledge gaps. While students take initiatives to help other members to the classroom or to expand the topic (Ex. 5, line 52), the teachers' management abilities are also important. In extract 5 , it is seen that the teacher successfully oriented to what student said and validated her response by asking further elaboration questions. In other words, she was able to orient to learners' contributions and shape their contributions and maintain the progressivity of the lesson serving the goals of the meaning and fluency contexts.

As a last teacher action to maintain learner turns in this interactional path, the teacher made extensive use of minimal response tokens (Ex. 2, lines 12 \& 17; Ex. 4, 
line 40; Ex. 5, lines 62 \& 64) and withheld evaluation turns. Initiation of okay and um um shows teacher's listenership and opens space for interaction (Girgin \& Brandt, 2019; Walsh, 2006). Withholding evaluation turns and postponing assessments are suggested by Waring (2008) and Wong and Waring (2009) in order not to suppress learning opportunities. Even when the teacher initiated good or very good answer which could be claimed as an EPA hindering learning opportunities (Wong \& Waring, 2009), the data revealed that the students kept taking turns and contributed to the interaction after the teacher's positive feedback turns in meaning and fluency contexts. Similar to the findings presented in Fagan (2014), this study shows that explicit positive assessments do not necessarily need to hinder further student turns. Rather, positive feedback turns in meaning and fluency contexts may encourage learners to continue and elaborate on their contributions. In other words, they may work as go-on markers and promote learner contributions in following turns. In this sense, this study adds to the literature that minimal response tokens show listenership and facilitate student talk, and initiating EPAs in meaning and fluency contexts is likely to promote and maintain student talk.

Overall, the present study tried to demonstrate one EFL teacher's interactional actions employed to promote and maintain extended student talk in a teacher-led Listening and Speaking course at tertiary level when the teacher targets meaning and fluency context. This micro-analytic study revealed the sequential organization of extended learner talk through use of teacher's enabling interactional moves and decisions. The findings may guide teachers to self-question their own practices in the classroom. They can self-examine to what extent they promote extended student talk or analyze the interactional resources they use to stimulate learner turns. In addition, teacher educators in practicum can teach trainees about the criticality of the contingent interactional decisions and moves to elicit learner talk in meaning and fluency contexts. In the light of the findings, teachers are recommended to provide students with preparation time in task completion, which also requires a careful planning before the lesson. Similarly, they are advised to be careful and selective about their questions and keep contingent questioning. Last but not least, they are advised to make use of every chance to open space for learning and modify their talk in order not to miss opportunities for possible longer student utterances when the focus is on meaning and fluency.

\section{Acknowledgements}

We would like to thank Prof. Dr. Hüsnü Enginarlar for his constructive feedback on the design of the present study and two anonymous reviewers for their insightful comments and suggestions.

\section{The Conflict of Interest Statement}

In line with the statement of Committee on Publication Ethics (COPE), we hereby declare that we had no conflicting interests regarding any parties of this study. 


\section{References}

Allwright, D., \& Bailey, K. M. (1991). Focus on the language classroom: An introduction to classroom research for language teachers. Cambridge: Cambridge University Press.

Amir, A. (2013). Self-policing in the language as a foreign language classroom. Novitas-ROYAL (Research on Youth and Language), 7(2), 84-105.

Bozbiyık, M. (2017). The Implementation of VEO in an English Language Education Context: A Focus on Teacher Questioning Practices. [Unpublished Master's Thesis]. Gazi University, Ankara.

British Council- TEPAV. (2015). The state of English in higher education in Turkey. British Council, Ankara.

Can-Daşkın, N. (2015). Shaping learner contributions in an EFL classroom: Implications for L2 Classroom Interactional Competence. Classroom Discourse, 6(1), 33-56. https://doi: 10.1080/19463014.2014.911699

Can-Daşkın, N., \& Hatipoğlu, Ç. (2019). Reference to a past learning event in teacher turns in an L2 instructional setting. Journal of Pragmatics, 142, 16-30.

Chaudron, C. (1988). Second language classrooms: Research on teaching and learning. Cambridge: Cambridge University Press.

Cook, V. (2013). Second Language Learning and Language Teaching. London: Routledge.

Duran, D. (2017). Student-initiated questions in English as a medium of instruction classrooms in a Turkish higher education setting. [Unpublished doctoral dissertation]. Hacettepe University, Ankara.

Eskildsen, S. W. (2018). 'We're learning a lot of new words': Encountering new L2 vocabulary outside of class. The Modern Language Journal, 102, 46-63. https://doi: 10.1111/modl.12451

Fagan, D.S. (2014). Beyond "excellent": Uncovering the systematicity behind positive feedback turn construction in ESL classrooms. Novitas-ROYAL (Research on Youth and Language), $8(1), 45-63$.

Gardner, R. (2013). Conversation analysis in the classroom. In J. Sidnell \& T. Stivers (Eds.), The Handbook of Conversation Analysis (pp. 593-611). Blackwell Publishing Ltd.

Garton, S. (2012). Speaking out of turn? Taking the initiative in teacher-fronted classroom interaction. Classroom Discourse, 3(1), 29-45. https://doi: 10.1080/19463014.2012.666022

Girgin, U., \& Brandt, A. (2019). Creating space for learning through 'Mm hm' in a L2 classroom: Implications for L2 classroom interactional competence, Classroom Discourse. https://doi: 10.1080/19463014.2019.1603115

Hall, J. K., \& Walsh, M. (2002). Teacher student interaction and language learning. Annual Review of Applied Linguistics, 22, 186-223.

Hall, J. K. (2000). Classroom interaction and language learning. In J. K. Hall \& L. S. Verplaetse (Eds.), Second and foreign language learning through classroom interaction (pp. 166-187). Mahwah, NJ: Lawrence Erlbaum Associates.

Hayano, K. (2013). Question design in conversation. In J. Sidnell \& T. Stivers (Eds.), The Handbook of Conversation Analysis (pp. 395-414). Blackwell Publishing Ltd.

Hellerman, J. (2003). The interactive work of prosody in the IRF exchange: Teacher repetition in feedback moves. Language in Society, 32(1), 79-104.

Hutchby, I., \& Wooffitt, R. (1998). Conversation analysis. Cambridge: Polity Press.

Huth, T. (2011). Conversation analysis and language classroom discourse. Language and Linguistics Compass, 5(5), 297-309. https://doi: 10.1111/j.1749-818x.2011.00277.x

Jacknick, C. (2011). "But this is writing": Post-expansion in student-initiated sequences. Novitas ROYAL (Research on Youth and Language), 5(1), 39-54. 
Jakonen, T., \& Morton, T. (2013). Epistemic search sequences in peer interaction in a contentbased language classroom. Applied Linguistics, 36(1), 73-94.

Jefferson, G. (2004). Glossary of transcript symbols with an introduction. In G. Lerner (Ed.), Conversation analysis: Studies from the first generation (pp. 13-31). Amsterdam: John Benjamins.

Juzwik, M. M., Borsheim-Black, C., Caughlan, S., \& Heintz, A. (2013). Inspiring dialogue: Talking to learn in the English classroom. New York: Teachers College Press.

Koshik, I. (2002a). Designedly incomplete utterances: A pedagogical practice for eliciting knowledge displays in error correction sequences. Research on Language and Social Interaction, 35(3), 277-309. https://doi: 10.1207/S15327973RLSI3503_2

Koshik, I. (2002b). A conversation analytic study of yes/no questions which convey reversed polarity assertions. Journal of Pragmatics, 34(12), 1851-1877. https://doi: 10.1016/S03782166(02)00057-7

Koshik, I. (2003). Wh-questions used as challenges. Discourse Studies, 5(1), 51-77.

Koshik, I. (2005). Alternative questions used in conversational repair. Discourse Studies, 7(2), 193-211.

Krashen, S. D. (1985). The input hypothesis: Issues and implications. New York: Longman.

Lee, Y. A. (2006). Respecifying display questions: Interactional resources for language teaching. TESOL Quarterly, 40(4), 691-713.

Lee, Y. A. (2007). Third turn position in teacher talk: Contingency and the work of teaching. Journal of Pragmatics, 39(1), 180-206. https://doi.org/10.1016/j.pragma.2006.11.003

Lee, Y. A. (2008). Yes-no questions in the third-turn position. Discourse Processes, 45(3), 237262. https://doi: 10.1080/01638530701739215

Lee, Y. A. (2010). Learning in the contingency of talk-in-interaction. Text and Talk, 30(4), 403422.

Margutti, P., \& Drew, P. (2014). Positive evaluation of student answers in classroom instruction. Language and Education, 28(5), 436-458.

Markee, N., \& Kasper, G. (2004). Classroom talks: An introduction. The Modern Language Journal, 88, 491-500.

Mehan, H. (1979). 'What time is it, Denise?": Asking known information questions in classroom discourse. Theory into Practice, 18(4), 285-294. https://doi: 10.1080/00405847909542846

Park, I. (2012). Asking different types of polar questions: the interplay between turn, sequence, and context in writing conferences. Discourse Studies, 14(5), 613-633.

Park, J. (2014). The roles of third turn repeats in two L2 classroom interactional contexts. Applied Linguistics, 35(2), 145-167.

Seedhouse, P. (2004). The Interactional architecture of the language classroom: A conversation analysis perspective. Malden: Blackwell.

Seedhouse, P. (2005). Conversation analysis and language learning. Language Teaching, 38, 165-187. https://doi: 10.1017/S0261444805003010

Sert, O. (2011). A micro-analytic investigation of claims of insufficient knowledge in EAL classrooms. [Unpublished PhD Thesis]. University of Newcastle upon Tyne.

Sert, O. (2013). Epistemic status check' as an interactional phenomenon in instructed learning settings. Journal of Pragmatics, 45, 13-28.

Sert, O. (2015). Social interaction and L2 classroom discourse. Edinburgh: Edinburgh University Press. 
Sert, O. (2017). Creating opportunities for L2 learning in a prediction activity. System, 70, 1425.

Swain, M. (1995). Three functions of output in second language learning. In G. Cook \& B.Seidlhofer (Eds.), Principle and practice in applied linguistics in honour of H. G. Widdowson (pp. 125-144). Oxford: Oxford University Press.

Swain, M., \& Carroll, S. (1987). The immersion observation study. In B. Harley, P. Allen, J. Cummins, \& M. Swain (Eds.), The development of bilingual proficiency final report (pp. 190-263). Toronto: Modern Language Centre, Ontario Institute for Studies in Education.

Walsh, S. (2002). Construction or obstruction: teacher talk and learner involvement in the EFL classroom. Language Teaching Research, 6(1), 3-23.

Walsh, S. (2006). Investigating classroom discourse. New York: Routledge.

Walsh, S. (2011). Exploring classroom discourse: Language in action. Abingdon, Oxon: Routledge.

Walsh, S. (2012). Conceptualising classroom interactional competence. Novitas-ROYAL (Research on Youth and Language), 6(1), 1-14.

Waring, H. Z. (2008). Using explicit positive assessment in the language classroom: IRF, feedback, and learning opportunities. The Modern Language Journal, 92, 576-594.

Waring, H.Z. (2009). Moving out of IRF (Initiation-Response-Feedback): A single case analysis. Language Learning, 59, 796-824.

Waring, H. Z. (2011). Learner initiatives and learning opportunities in the language classroom. Classroom Discourse, 2(2), 201-218.

Waring H. Z. (2012). Yes-no questions that convey a critical stance in the language classroom. Language and Education, 26(5), 451-469. https://doi: 10.1080/09500782.2012.656651

Waring, H. Z. (2016). Theorizing pedagogical interaction: Insights from conversation analysis. New York: Routledge.

Wong J., \& Waring, H. Z. (2009). 'Very good' as a teacher response. ELT Journal, 63(3), 195203.

Young, R. (1999). Sociolinguistic approaches to SLA. Annual Review of Applied Linguistics, 19, 105-132.

Yüksel, D. (2014). Teachers' treatment of different types of student questions. Classroom Discourse, 5(2), 176-193. https://doi: 10.1080/19463014.2014.893894

\section{Appendix A. Transcription Conventions}

The transcription system uses standard punctuation marks (comma, stop, question mark); however, in the system they mark intonation rather than syntax. Arrows are used for more extreme intonational contours and should be used sparingly. The system marks noticeable emphasis, volume shifts, and so on. A generally loud speaker should not be rendered in capitals throughout.

$\uparrow \downarrow \quad$ Vertical arrows precede marked pitch movement, over and above normal rhythms of speech. They are used for notable changes in pitch beyond those represented by stops, commas and question marks.

$\rightarrow \quad$ Side arrows are used to draw attention to features of talk that are relevant to the current analysis.

Underlining indicates emphasis; the extent of underlining within individual words locates emphasis and also indicates how heavy it is. 
CAPITALS mark speech that is hearably louder than surrounding speech. This is beyond the increase in volume that comes as a by product of emphasis.

`^I know it, ' 'degree' signs enclose hearably quieter speech.

(0.4) Numbers in round brackets measure pauses in seconds (in this case, 4 tenths of a second). If they are not part of a particular speaker's talk they should be on a new line. If in doubt use a new line.

(.) A micropause, hearable but too short to measure.

((stoccato)) Additional comments from the transcriber, e.g. about features of context or delivery.

she wa::nted Colons show degrees of elongation of the prior sound; the more colons, the more elongation.

y'know? Question marks signal stronger, 'questioning' intonation, irrespective of grammar.

Yeh. Full stops mark falling, stopping intonation ('final contour'), irrespective of grammar, and not necessarily followed by a pause.

bu-u- hyphens mark a cut-off of the preceding sound.

$>$ he said< 'greater than' and 'lesser than' signs enclose speeded-up talk. Occasionally they are used the other way round for slower talk.

solid. $==$ We had 'Equals' signs mark the immediate 'latching' of successive talk, whether of one or more speakers, with no interval.

heh heh Voiced laughter. Can have other symbols added, such as underlinings, pitch movement, extra aspiration, etc.

sto(h)p i(h)t Laughter within speech is signalled by h's in round brackets.

* One of the reviewers commented that this turn can be a teacher's increment.

\section{Copyrights}

Copyright for this article is retained by the author(s), with first publication rights granted to the Journal.

This is an open-access article distributed under the terms and conditions of the Creative Commons Attribution license (CC BY-NC-ND) (http://creativecommons.org/licenses/by-nc-nd/4.0/). 